\title{
Efficacy Evaluation of 755-nm Long-Pulse Alexandrite Laser Combined with $0.5 \%$ Timolol Maleate Eye Drops in the Treatment of Thicker Infantile Hemangioma
}

Jianming $\mathrm{Wu}^{*}$

Fangyan Zhou*

Yu Gao

Department of Dermatological, Yuying Children's Hospital, The Second Affiliated Hospital of Wenzhou Medical University, Wenzhou, Zhejiang, 325000, People's Republic of China

*These authors contributed equally to this work
Correspondence: Yu Gao Email 570875734@qq.com
Purpose: Assessment of the clinical effectiveness and safety of 755-nm long-pulse alexandrite laser combined with $0.5 \%$ timolol maleate eye drops in treating thicker infantile hemangioma (IH).

Materials and Methods: Retrospective analysis of IH treated with 755-nm long-pulse alexandrite laser and topical timolol in the Second Affiliated Hospital of Wenzhou Medical University from October 2019 to October 2020. Seventy-eight cases were included, with a five-week laser treatment interval. Treatment status was documented during the 35 weeks before each treatment, the effect was assessed at the visual analog scale (VAS), and side effects were recorded. During the 6-month follow-up period, the recurrence and residual skin lesions were monitored. The relationship between IH thickness, treatment duration and VAS was analyzed.

Results: Among the 78 children with hemangioma, 4 children were treated with a combination of propranolol, fractional laser and cinnamyl alcohol injection due to poor curative effect. Finally, the lesions were effectively alleviated. At the 5th, 15th, 25 th, and 35 th weeks of treatment, the average VAS of 74 children were $3.56 \pm 1.20,4.61 \pm 1.43,5.63 \pm 1.60$, and $6.63 \pm 1.72$, respectively. We analyzed VAS in different thickness groups with Repeated Measures Analysis of Variance(RMANOVA). The results show that the VAS of the thickness $2-3 \mathrm{~mm}$ and $3-5 \mathrm{~mm}$ groups were higher than the $5-7 \mathrm{~mm}$ and $7-8 \mathrm{~mm}$ groups ( $\mathrm{F}$ group $=$ $440.54, \mathrm{P}<0.05, \mathrm{~F}$ time $=448.31, \mathrm{P}<0.05$ ). During the 6-month follow-up period, none of the 74 children relapsed and the residual skin lesions gradually vanished.

Conclusion: Combined treatment of IHs with a 755-nm long-pulse alexandrite laser and $0.5 \%$ timolol maleate eye drops which has apparent clinical efficacy and safety reduce residual skin lesions and decrease the $\mathrm{IH}$ recurrence rate.

Keywords: infantile hemangioma, 755-nm long-pulse alexandrite laser, timolol maleate eye drops, thick

\section{Introduction}

In infants and young children, the incidence of hemangioma is $4-10 \%$, and the male to female ratio is approximately $1: 1.4{ }^{1}$ It is the most common benign tumor of infancy. Infantile hemangioma (IH) usually does not exist at birth and appears immediately (within a few weeks) after birth. The evolution of IH follows a typical three-stage pattern. The first stage, 6-9 months, is characterized by the proliferation of immature endothelial cells. Then, it enters a plateau period, and there is no 
growth trend. Finally, $90 \%$ of children naturally return to normal before the age of 9 years. $^{2}$ Due to the possibility of natural regression of $\mathrm{IH}$, some families prefer to wait, taking no action. However, $10-15 \%$ of IHs run the risk of ulceration, dysfunction, and disfigurement, so such cases require formal treatment on time. ${ }^{3}$ Currently, there are many treatments for $\mathrm{IH}$, including laser, $\beta$-blockers, surgery, and cryotherapy. Among these, lasers and $\beta$ blockers are widely used.

At present, laser treatment of superficial IH is mainly based on pulsed dye laser (PDL) (wavelength $585 \mathrm{~nm}$ or $595 \mathrm{~nm})$ and the non-selective $\beta$-blocker timolol. ${ }^{4-6}$ According to the existing literature, $\mathrm{IH}>2 \mathrm{~mm}$ is regarded as thicker IH. ${ }^{7-9}$ However, PDL has insufficient penetration depth for thicker IH, so the treatment result is not ideal. ${ }^{10,11}$ Therefore, some scholars advocate using 1064 $\mathrm{nm} \mathrm{Nd}$ : YAG with deeper penetration to treat thicker IHs. However, the challenge of the laser in the treatment of vascular diseases is the narrowing of the therapeutic window, which could easily lead to serious side effects. ${ }^{12-14}$ Therefore, the PDL and $1064 \mathrm{~nm} \mathrm{Nd:} \mathrm{YAG} \mathrm{laser} \mathrm{are} \mathrm{not}$ the best choices for thicker IH.

In addition to lasers, $\beta$-blockers are effective in treating IH. ${ }^{15-17}$ Among them, the non-selective beta-blocker timolol has become the first-line topical drug for treating superficial $\mathrm{IH}^{6}{ }^{6}$ Moreover, its action intensity is eight times that of propranolol. In recent years, the literature has shown that topical timolol can replace oral propranolol as a first-line treatment for superficial IH, with higher clinical efficacy and safety. ${ }^{18}$

Recently, some scholars have used a 755-nm long-pulse alexandrite laser to treat $\mathrm{IH}$ and varicose veins and have achieved significant effects. ${ }^{19-21}$ Since the $755-\mathrm{nm}$ longpulse alexandrite laser has a longer wavelength and a more profound penetrating ability, it may be a new and effective way to treat thicker IH. However, according to clinical experience, when the 755-nm long-pulse alexandrite laser is used alone to treat thicker IHs in the later stage, most IHs will have residual skin lesions. B-ultrasound results showed that most residual skin lesions were relatively superficial. Therefore, a 755-nm long-pulse alexandrite laser combined with $0.5 \%$ timolol maleate eye drops or PDL may be more effective in treating thicker IHs. However, according to the clinical situation, a 755-nm long-pulse alexandrite laser combined with $0.5 \%$ timolol maleate eye drops are more readily accepted by the patient's family.

This study aimed to retrospectively analyze the efficacy of a 755-nm long-pulse alexandrite laser combined with $0.5 \%$ timolol maleate eye drops on thicker IHs and the possible adverse reactions to provide data for the clinical treatment of thicker IHs.

\section{Materials and Methods}

The independent ethics committee approved this study of the Second Affiliated Hospital of Wenzhou Medical University and Yuying Children's Hospital and it was conducted following the Declaration of Helsinki. We have obtained the prior consent of all patient guardians to keep the photos in our files for medical purposes. Moreover, we have obtained written informed consent from all patient guardians before participating in the study.

Patient Clinical Data: In this retrospective observational study, we collected from October 2019 to October 2020 in the Dermatology Clinic of the Second Affiliated Hospital of Wenzhou Medical University who received 755-nm long-pulse alexandrite laser combined with $0.5 \%$ timolol maleate eye drops for topical treatment IH. (1) IH that meets the relevant diagnostic criteria in the Guidelines for the Diagnosis and Treatment of Hemangiomas and Vascular Malformations in $2019 ;{ }^{22}$ (2) B-ultrasound manifested the thickness of the $\mathrm{IH}$ is greater than $2 \mathrm{~mm}$ and less than or equal to $8 \mathrm{~mm}$; (3) The child has not received other treatments before diagnosis and treatment; (4) Children with multiple lesions were excluded. (5) Children with skin lesions on the scalp, eyelids and perineum were excluded. A total of 78 children with IH were collected, including 21 males $(26.9 \%)$ and 57 females (73.1\%), with an age of $(4.5 \pm 1.4)$ months (range 22 days to about 6 months). The treatment status of all children was collected in the previous 35 weeks. VAS evaluation was performed during the treatment at the 5th, 15th, 25th, and 35th weeks, and the side effects were recorded. Six months of followup after treatment, and recorded the recurrence rate and residual skin lesions. The relationship between IH thickness, treatment time and VAS was analyzed.

Therapy: 755-nm long-pulse alexandrite laser treatment instrument, produced by Candela Laser Company, USA, laser treatment parameters: wavelength $755 \mathrm{~nm}$, pulse width $3 \mathrm{~ms}$, energy density $45-55 \mathrm{~J} / \mathrm{cm},{ }^{2}$ spot diameter $8 \mathrm{~mm}$. During the treatment, the refrigerant spray of the Dynamic Cooling Device (DCD) was injected at $20 \mathrm{~ms}$ intervals. Before the treatment, children were taken photographs. Besides, the family members were informed of possible risks and prognosis, and signed the consent form.

Efficacy criteria and methods: All patients were photographed by the same researcher before each treatment with the same camera and the photo parameters, in 
the same conditions and angles. A dermatologist evaluated the curative effect on the spot based on the patient's actual situation and estimated IH's color, size, and texture changes. The curative effect evaluation method uses VAS. The VAS value is $-10-10$. -10 means that the color and texture of the tumor has doubled, 0 means that there is no change, 10 means that the tumor has completely subsided, and the IH score before the first treatment is all 0 points. ${ }^{23}$ The results of each evaluation were the average of the scores of 3 dermatologists, and the same 3 dermatologists completed each score. The VAS scores were recorded at $5,15,25$, and 35 weeks of treatment.

\section{Statistical Analysis}

SPSS23.0 is used for statistical analysis, and Graph pad prism 7 is selected for drawing software. The efficacy score of $\mathrm{IH}$, VAS, is expressed as $\mathrm{x} \pm \mathrm{s}$, and the statistical analysis method is RMANOVA; $\mathrm{P}<0.05$ indicates that the difference is statistically significant.

\section{Results}

A total of 78 children with $\mathrm{IH}$ were treated with $755-\mathrm{nm}$ long-pulse alexandrite laser combined with $0.5 \%$ timolol maleate eye drops for topical treatment (excluding $\mathrm{IH}$ located on the scalp, eyelid and perineum cases), including 21 males (26.9\%) and 57 females (73.1\%). 23 (29.5\%) cases were $0-2$ months, $25(32.1 \%)$ cases were 3-4 months, $30(38.5 \%)$ cases were 5-6 months, with an average of (4.5 $\pm 1.4)$ months. $17(21.8 \%)$ cases of IH were on the face, 31 $(39.7 \%)$ were on the trunk, $21(26.9 \%)$ were on the limbs, and $9(11.5 \%)$ were on the hands and feet. B-ultrasound showed $20(25.6 \%)$ cases with thickness of $2-3 \mathrm{~mm}, 32$ $(41.0 \%)$ cases with $3-5 \mathrm{~mm}, 16(20.5 \%)$ cases with $5-7 \mathrm{~mm}$, and $10(12.8 \%)$ cases with $7-8 \mathrm{~mm}$. We extract data about gender, age, location and thickness of IH from each eligible case (Table 1).

A total of 78 cases received 755-nm long-pulse alexandrite laser combined with $0.5 \%$ timolol maleate eye drops for topical treatment, most of them had a significant effect. However, 4 cases began to thicken after 35 weeks. Four cases were all relieved effectively, receiving a combination of propranolol, fractional laser, and cinnamyl alcohol injection treatment (Figure 1).

In the initial IH thickness 2-3 mm group of 20 patients, the VAS at the 5 th week of treatment was $4.32 \pm 0.70$. As the treatment progressed, the VAS increased to $5.98 \pm 0.42$ at the 15 th week, and the VAS reached $7.11 \pm 0.46$ at the 25 th week. At the 35 th week, the VAS can reach $8.24 \pm$
Table I Baseline Characteristics at Time of Inclusion

\begin{tabular}{|l|c|}
\hline Characteristics & IH (n=78) \\
\hline $\begin{array}{l}\text { Sex, } \mathbf{n}(\%) \\
\text { Fale }\end{array}$ & $21(26.9 \%)$ \\
Female & $57(73.1 \%)$ \\
\hline Age at the time of first visit (months) & \\
$0-2$ & $23(29.5 \%)$ \\
$3-4$ & $25(32.1 \%)$ \\
$5-6$ & $30(38.5 \%)$ \\
\hline Location, $\mathbf{n}$ (\%) & \\
Face & $17(21.8 \%)$ \\
Trunk & $31(39.7 \%)$ \\
Limbs & $21(26.9 \%)$ \\
Extremity & $9(11.5 \%)$ \\
\hline Tumor thickness (The maximum value is & \\
included in the group, but the minimum value is & \\
not included) & \\
$2-3 m m$ & $20(25.6 \%)$ \\
$3-5 m m$ & $32(41.0 \%)$ \\
$5-7 m m$ & $16(20.5 \%)$ \\
$7-8 m m$ & $10(12.8 \%)$ \\
\hline
\end{tabular}

Note: As the percentage data is rounded, it may appear that the total is greater than or less than $100 \%$.

0.47. Initially, 32 patients in the IH thickness 3-5 $\mathrm{mm}$ group, the VAS was $4.15 \pm 0.69$ at the 5 th week of treatment. With the extension of the treatment time, the VAS at the 15 th and 25 th weeks showed a steadily increasing trend. At the 35 th week, the VAS could reach $7.32 \pm 0.42$, and satisfactory results can still be obtained. However, the VAS of the 5$7 \mathrm{~mm}$ group and the $7-8 \mathrm{~mm}$ group were $2.17 \pm 0.45$ and 1.67 \pm 0.38 at the 5 th week, respectively. Moreover, the VAS of the two groups were $4.51 \pm 0.33$ and $3.56 \pm 0.30$ at the 35 th week, respectively. VAS analysis of variance of repeated measurement data at each time point between different thickness groups $(\mathrm{F}$ group $=440.54, \mathrm{P}<0.05, \mathrm{~F}$ time $=$ 448.31, $\mathrm{P}<0.05)$. That is, in the 755-nm long-pulse alexandrite laser combined with $0.5 \%$ timolol maleate eye drops, the difference in VAS between the different thickness groups at each time point was statistically significant. The final VAS scores of the 2-3 $\mathrm{mm}$ group and the $3-5 \mathrm{~mm}$ group were higher than that of the $5-7 \mathrm{~mm}$ group and the $7-8 \mathrm{~mm}$ group. We summarize the VAS at each time point of IH in different thickness groups (Table 2 and Figure 2).

\section{Adverse Reactions}

A total of 16 cases $(21.6 \%)$ showed varying degrees of redness, blisters, scab and pigment change, of which 6 cases $(8.1 \%)$ redness and swelling, 3 cases $(4.1 \%)$ blisters and 5 


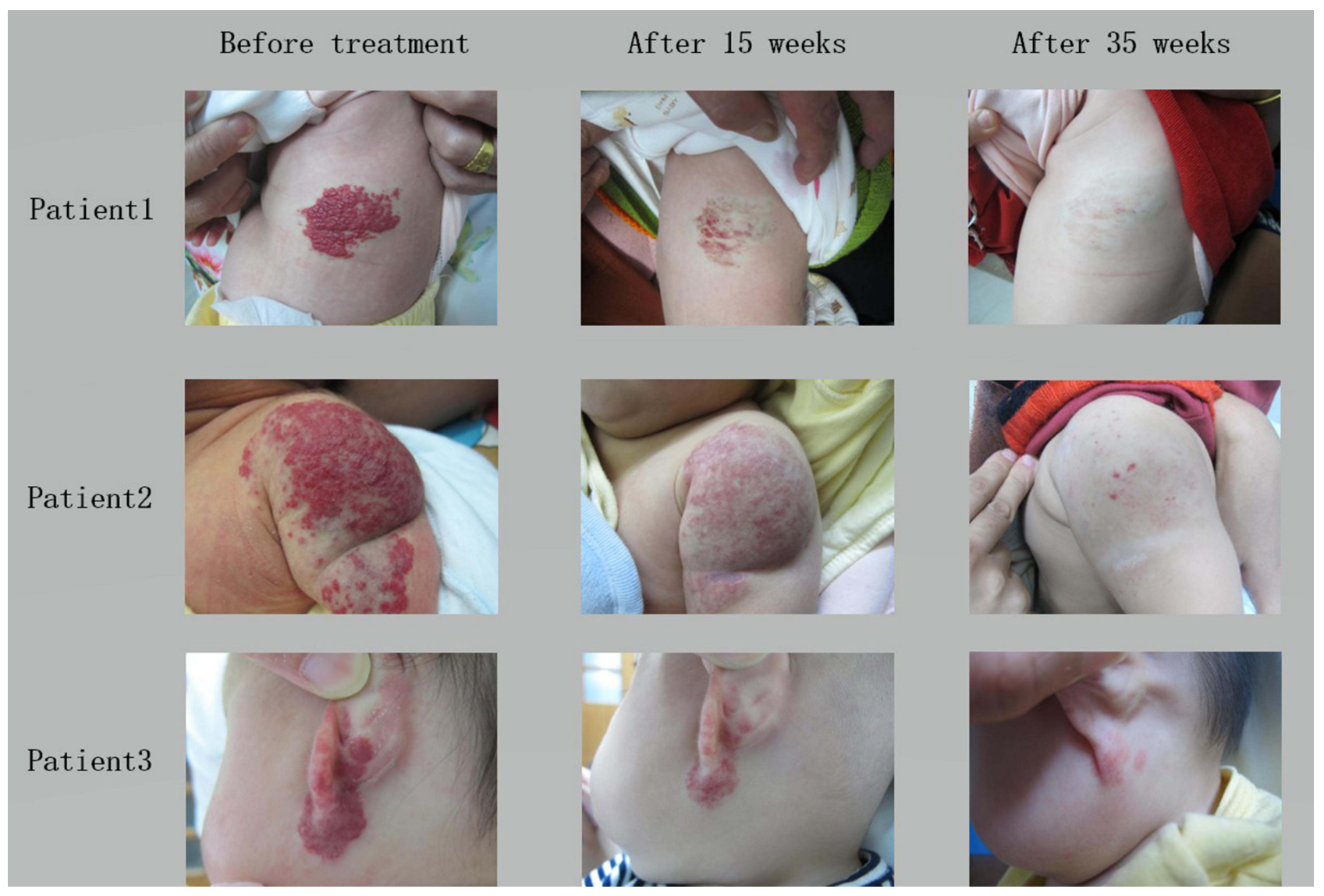

Figure I IH treatment with 755-nm long-pulse alexandrite laser combined with $0.5 \%$ timolol maleate eye drops. Patients and laser treatment situation: Patient I: 6 months, male, B-ultrasound: $5 \mathrm{~mm}, 3$ times, $3 \mathrm{~ms}, 40 \mathrm{~J} / \mathrm{cm}^{2}$. Patient 2: 5 months, female, B-ultrasound: $8 \mathrm{~mm}, 6$ times, $3 \mathrm{~ms}, 45 \mathrm{~J} / \mathrm{cm}^{2}$. Patient 3: $4 \mathrm{months}$, male, B-ultrasound: $7 \mathrm{~mm}, 6$ times, $3 \mathrm{~ms}, 45 \mathrm{~J} / \mathrm{cm}^{2}$.

cases $(6.8 \%)$ scab. All the adverse reactions were significantly relieved after 1 to 2 weeks of topical treatment with Fucidic cream, Befuji (topical treatment with recombinant bovine basic fibroblast growth factor) and He-Ne laser. There were no severe complications such as infection and scar. 2 cases $(2.7 \%)$ developed pigmentation after treatment, and it gradually returned to normal within 6 months of follow-up. We summarize the side effects of 755-nm long-pulse alexandrite laser combined with $0.5 \%$ timolol maleate eye drops in the treatment of 74 cases of IH (Table 3 and Figure 3).

\section{Residual Skin Lesions and Recurrence Rates}

During the 6-month follow-up period, none of the 74 children relapsed and the residual skin lesions gradually vanished.

\section{Discussion}

In this study, we retrospectively analyzed the curative effect of the 755-nm long-pulse alexandrite laser combined

Table 2 The VAS at Each Time Point of IH in Different Thickness Groups

\begin{tabular}{|l|c|c|c|c|c|c|}
\hline \multirow{2}{*}{ Intervention } & \multirow{2}{*}{ Thickness } & \multirow{N}{*}{$\mathbf{N}$} & \multicolumn{4}{|c|}{ VAS $(\overline{X \pm S})$} \\
\cline { 4 - 7 } & & & $\mathbf{5}$ Weeks & 15 Weeks & 25 Weeks & $\mathbf{3 5}$ Weeks \\
\hline $\mathbf{7 5 5 n m}$ combined with timolol & $2-3 \mathrm{~mm}$ & 20 & $4.32 \pm 0.70$ & $5.98 \pm 0.42$ & $7.11 \pm 0.46$ & $8.24 \pm 0.47$ \\
$(\mathbf{n = 7 4 )}$ & $3-5 \mathrm{~mm}$ & 32 & $4.15 \pm 0.69$ & $5.10 \pm 0.56$ & $6.23 \pm 0.52$ & $7.32 \pm 0.42$ \\
& $5-7 \mathrm{~mm}$ & 14 & $2.17 \pm 0.45$ & $3.02 \pm 0.31$ & $3.81 \pm 0.40$ & $4.51 \pm 0.33$ \\
& $7-8 \mathrm{~mm}$ & 8 & $1.67 \pm 0.38$ & $2.01 \pm 0.29$ & $2.73 \pm 0.35$ & $3.56 \pm 0.30$ \\
\hline
\end{tabular}




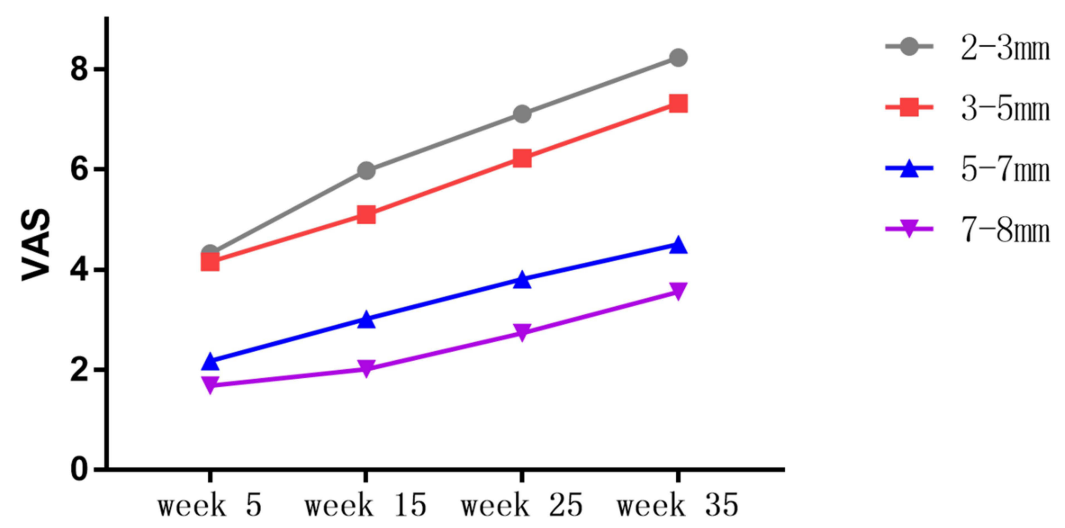

Figure 2 VAS at each time point of $\mathrm{IH}$ in different thickness groups treated with 755 -nm long-pulse alexandrite laser combined with $0.5 \%$ timolol maleate eye drops.

with $0.5 \%$ timolol maleate eye drops for topical treatment in 78 patients from the dermatology department of our hospital at week 5 through 35 . Because the 755-nm longpulse alexandrite laser is not suitable for treating IHs in the scalp (areas that require hair growth), eyelids, and perineal area (thinner skin), this study excluded cases with IHs located in these areas. The results indicate that the optimal results of the 755-nm long-pulse alexandrite laser treatment combined with $0.5 \%$ timolol maleate eye drops for topical application were observed in patients with IH with a thickness of 2-5 mm. The incidence of side effects was low, with just 16 cases $(21.6 \%)$ manifesting redness, blisters, scabs, and abnormal pigmentation.

Laser therapy is an effective method for treating IHs. As early as 1983, Anderson et al. ${ }^{24}$ proposed the theory of selective photothermal action, which led to a precedent for treating skin vascular diseases in infants and young children with laser. Multiple studies have shown that the vast majority of children with IH are susceptible to laser treatment. After laser treatment, the plasma concentration of vascular endothelial growth factor (VEGF) and basic fibroblast growth factor (bFGF) that promote vascular proliferation can be significantly reduced, and ultimately,

Table 3 Side Effects of 755-nm Long-Pulse Alexandrite Laser Combined with $0.5 \%$ Timolol Maleate Eye Drops in the Treatment of 74 Cases of $\mathrm{IH}$

\begin{tabular}{|l|l|l|l|l|}
\hline $\begin{array}{l}\text { Location/Side } \\
\text { Effects (n/N) }\end{array}$ & Swelling & Blister & Scab & $\begin{array}{l}\text { Pigment } \\
\text { Change }\end{array}$ \\
\hline Face & $1 / 16$ & $1 / 16$ & $0 / 16$ & $1 / 16$ \\
Trunk & $2 / 29$ & $1 / 29$ & $3 / 29$ & $0 / 29$ \\
Limbs & $2 / 20$ & $1 / 20$ & $1 / 20$ & $0 / 20$ \\
Extremity & $1 / 9$ & $0 / 9$ & $1 / 9$ & $1 / 9$ \\
\hline
\end{tabular}

good clinical results are achieved. ${ }^{25}$ However, a fraction of children with IH have low sensitivity to laser treatment. After laser treatment, the plasma concentrations of VEGF and bFGF remain high or even increase. In children with IH, laser therapy can be combined with glucocorticoid therapy, oral propranolol, and local sclerosing agent injections. ${ }^{26}$ In this study, in the first 35 weeks, the 755$\mathrm{nm}$ long-pulse alexandrite laser combined with $0.5 \%$ timolol maleate eye drops had an excellent effect as a topical treatment in four children. Due to the poor curative effect and the constant thickening of the IHs, treatments continued after 35 weeks are insensitive to the laser. At that later stage of the treatment, a combination of propranolol, fractional laser, and cinnamyl alcohol injection effectively relieve the IHs.

In addition to significantly reducing the plasma concentrations of VEGF and bFGF in the plasma of children with $\mathrm{IH}$, the principle of laser treatment of IH is that the oxygenated hemoglobin $(\mathrm{OHB})$ and the deoxygenated hemoglobin (DHB) show absorption peaks. ${ }^{27}$ After the expected chromophores OHB and DHB absorb the laser of the corresponding band, photothermal coagulation contributes within milliseconds to convert oxyhemoglobin into methemoglobin and form a thrombus, which leads to the degeneration and necrosis of vascular endothelial cells. Although OHB and DHB in blood vessels have absorption peaks in the near-infrared region (700-1100 nm), they have higher absorption peaks at 418,542 , and $577 \mathrm{~nm},{ }^{27,28}$ so the absorption rates of $\mathrm{OHB}$ and DHB for PDL are significantly higher than those for the 755-nm long-pulse alexandrite laser. However, the penetration depth of PDL is only $2 \mathrm{~mm}$, which may be only $1 / 10$ of the thickness of some IHs, and IHs thicker than $2 \mathrm{~mm}$ can be regarded as thicker $\mathrm{IHs}^{7-9}$ In the early stage, when the thickness of IH is $<2 \mathrm{~mm}$, PDL shows excellent results, ${ }^{29,30}$ 


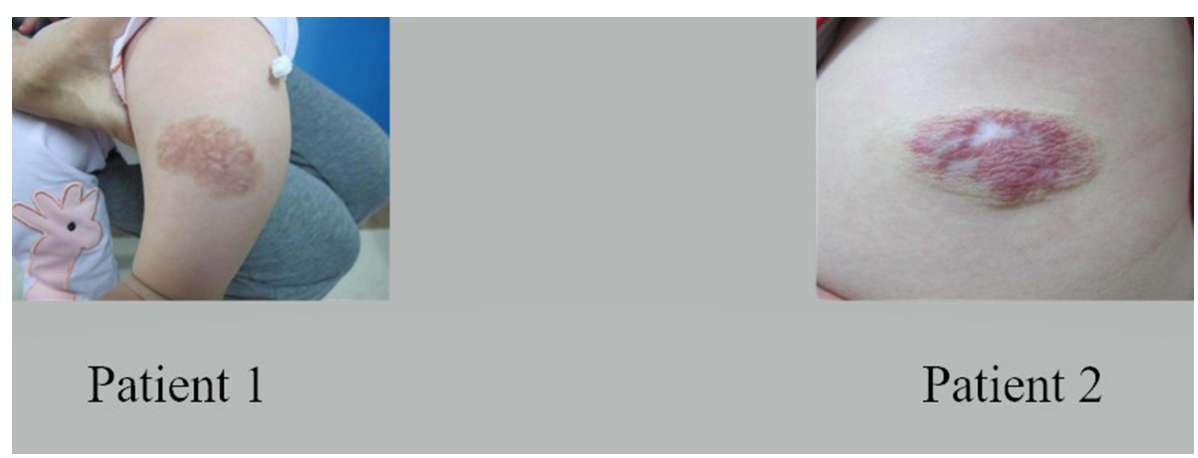

Figure 3 Patient I After 5 times of topical treatment with 755-nm long-pulse alexandrite laser combined with $0.5 \%$ timolol maleate eye drops, the pigmentation appeared, and the pigmentation subsided within 6 months of follow-up. Patient 2 After 755 -nm long-pulse alexandrite laser combined with $0.5 \%$ timolol maleate eye drops for topical treatment for 6 times, hypopigmentation appeared and returned to normal within 6 months after the end of the treatment.

but for IHs with a thickness $>2 \mathrm{~mm}$, both clinical observations and literature studies show that the final curative effect is unsatisfactory. ${ }^{19,29,31}$ According to reports, the penetration depth of a 755 -nm long-pulse alexandrite laser is $50-75 \%$ deeper than that of PDL. ${ }^{19}$ Therefore, the 755-nm long-pulse alexandrite laser has certain advantages over PDL in treating thicker IHs.

Studies have shown that $1064 \mathrm{~nm} \mathrm{Nd:} \mathrm{YAG} \mathrm{also} \mathrm{has}$ apparent advantages in penetration depth over PDL, and the penetration depth is $60-80 \%$ deeper than that of PDL. ${ }^{19,32}$ However, the absorption rate of OHB and DHB for this type of laser is low, so it is necessary to increase the energy to achieve treatment. However, higher energy indicates a greater probability of thermal skin damage. Therefore, when using $1064 \mathrm{~nm} \mathrm{Nd:} \mathrm{YAG} \mathrm{to} \mathrm{treat} \mathrm{IHs,} \mathrm{it} \mathrm{is} \mathrm{not} \mathrm{only} \mathrm{neces-}$ sary to use DCD to prevent thermal damage, but also to adopt conservative treatment parameters, carefully observe over time, and provide the child a mask and cold compress immediately after treatment. However, compared with the 755-nm long-pulse alexandrite laser, the $1064 \mathrm{~nm}$ Nd: YAG laser has a very narrow treatment window. Therefore, an inexperienced doctor may cause purpura and severe skin damage, ${ }^{19}$ manifested as blisters and scars while adjusting the energy. ${ }^{12-14}$ Therefore, even with the above protective measures, it can easily cause serious side effects, which highly depend on the doctor's experience. With the use of a 755-nm long-pulse alexandrite laser to treat IHs, there might be a need to increase the laser's energy; therefore, there is also the risk of serious complications. Fortunately, none of the cases included in this study presented serious side effects, such as scars, deformities, and functional damage. This may be related to the application of conservative treatment parameters, DCD cooling settings, and timely follow-up treatment. Thus, the PDL and the 1064 nm Nd: YAG lasers have certain limitations for treating thicker IHs. The 755-nm long-pulse alexandrite laser has a moderate wavelength, which ensures a certain depth of penetration. Also, the absorption capacity of hemoglobin is similar to that of $1064 \mathrm{~nm} \mathrm{Nd:} \mathrm{YAG.} \mathrm{Therefore,} \mathrm{a} \mathrm{755-}$ $\mathrm{nm}$ long-pulse alexandrite laser is expected to become the new treatment choice for IHs.

Various studies have investigated the use of a 755-nm long-pulse alexandrite laser to treat thicker IHs.

Jin et al. ${ }^{20}$ detailed the efficacy of a 755-nm longpulse alexandrite laser combined with PDL in treating IHs. The treatment has achieved good results, indicating that the combined treatment is effective for thicker IHs. The study shows that the 755-nm long-pulse alexandrite laser has unique advantages in the treatment of IHs. It can compensate for the defect of insufficient penetration depth of the PDL. At the same time, hemoglobin has an absorption peak at the $755 \mathrm{~nm}$ spectrum, which can form thrombi in blood vessels and cause vascular necrosis.

Su et al. ${ }^{21}$ conducted a retrospective study of 48 children undergoing IH treatment with a $755-\mathrm{nm}$ long-pulse alexandrite laser for 1 year. The results suggested that IHs respond well to a 755-nm long-pulse alexandrite laser with fewer complications. The author analyzed the principle of the 755-nm long-pulse alexandrite laser treatment of IHs and its feasibility thoroughly. It has been observed that the treatment of IHs of the trunk and limbs is more effective and they improve faster than IHs of the face, neck, and extremities. In addition, the age at the first treatment, sex, and whether the IH was proliferating were significantly correlated with the degree of IH improvement.

Ross et al..$^{33}$ conducted a prospective study and treated 15 patients with dilated superficial calf veins with $755-\mathrm{nm}$ 
long-pulse alexandrite laser treatment. The results suggest that the 755-nm long-pulse alexandrite laser significantly affects superficial vein dilation, and no apparent complications have occurred. The principle is that the laser is sufficient to heat the vascular endothelium and the surrounding matrix. Due to thermal degeneration, the vascular wall shrinks, and the heat-damaged endothelial cells and surrounding tissues cause a series of micro thromboses and inflammation. Finally, the blood vessels were replaced by fibrous tissue.

Therefore, a 755-nm long-pulse alexandrite laser may be an effective treatment for thicker IHs. However, according to the author's clinical experience, when a 755-nm long-pulse alexandrite laser alone is used to treat thicker IHs in the later stage, most IHs will have residual skin lesions. B-ultrasound results showed that most residual skin lesions were relatively superficial. According to other reports on the treatment of superficial IHs, PDL combined with the topical nonselective $\beta$-blocker timolol is recognized as an effective treatment. ${ }^{29,34}$ However, the high cost of the PDL treatment and the need for doctors trained to provide it prevent smaller hospitals from acquiring this equipment. Thus, patients should visit a higher-level hospital to look for that treatment regularly, which may compromise the treatment. Moreover, as topical timolol eye drops cost less, the patient's acceptance is higher because patients can administrate treatment themselves and follow up by telephone later.

Therefore, a 755-nm long-pulse alexandrite laser combined with $0.5 \%$ timolol maleate eye drops for topical treatment of thicker IHs, instead of PDL, can reduce the residual superficial skin lesions, thus facilitating patient acceptance and clinical implementation. This retrospective analysis of the 755-nm long-pulse alexandrite laser combined with $0.5 \%$ timolol maleate eye drops in 74 cases of thicker IHs confirmed our hypothesis. In addition, $0.5 \%$ timolol maleate eye drops were used for maintenance treatment for 6 months in the later stage. There was no recurrence, and the residual skin lesions were reduced or even disappeared completely compared with those at the end of treatment. The patients were delighted in their follow-up visit. However, this study lacked a strict control group. Prospective comparison and clinical control studies are needed in the later stage to confirm the effectiveness of this treatment regimen.

Combined treatment of IHs with a 755-nm long-pulse alexandrite laser and $0.5 \%$ timolol maleate eye drops has apparent clinical efficacy and safety. In addition, it can reduce residual skin lesions and decrease the $\mathrm{IH}$ recurrence rate.

\section{Disclosure}

None of the authors has a conflict of interest.

\section{References}

1. Frieden IJ, Haggstrom AN, Drolet BA, et al. Infantile hemangiomas: current knowledge, future directions. Proceedings of a research workshop on infantile hemangiomas, April 7- 9, 2005, Bethesda, Maryland, USA. Pediatr Dermatol. 2005;22(5):383-406. doi:10.1111/j.1525-1470.2005.00102.x

2. Dickison P, Christou E, Wargon O. A prospective study of infantile hemangiomas with a focus on incidence and risk factors. Pediatr Dermatol. 2011;28(6):663-669. doi:10.1111/j.1525-1470.2011.01568.x

3. Léauté-Labrèze C, Prey S, Ezzedine K. Infantile haemangioma: part II. Risks, complications and treatment. J Eur Acad Dermatol Venereol. 2011;25(11):1254-1260. doi:10.1111/j.1468-3083.2011.04105.x

4. Tay YK, Tan SK. Treatment of infantile hemangiomas with the 595-nm pulsed dye laser using different pulse widths in an Asian population. Lasers Surg Med. 2012;44(2):93-96. doi:10.1002/lsm.21159

5. Zhang W, Li F, Yang Y, et al. Hemangioma treatment with pulsed dye laser-distinct parameters used between neonatal and non-neonatal patients. J Cosmet Laser Ther. 2016;18(7):389-392. doi:10.1080/ 14764172.2016.1197402

6. Zheng L, Li Y. Effect of topical timolol on response rate and adverse events in infantile hemangioma: a meta-analysis. Arch Dermatol Res. 2018;310(4):261-269. doi:10.1007/s00403-018-1815-y

7. Feng H, Kauvar ANB. Successful treatment of a residual, thick, infantile hemangioma in a darker phototype pediatric patient using the 755-nm long-pulsed alexandrite laser. Dermatol Surg. 2017;43 (12):1514-1516. doi:10.1097/DSS.0000000000001144

8. Tennant LB, Mulliken JB, Perez-Atayde AR, Kozakewich HPW. Verrucous hemangioma revisited. Pediatr Dermatol. 2006;23 (3):208-215. doi:10.1111/j.1525-1470.2006.00219.x

9. Su WT, Xue JX, Ke YH. Noteworthy effects of a long-pulse Alexandrite laser for treatment of high-risk infantile hemangioma: a case report and literature review. World J Clin Cases. 2019;7 (14):1876-1883. doi:10.12998/wjcc.v7.i14.1876

10. Ashinoff R, Geronemus RG. Failure of the flashlamp-pumped pulsed dye laser to prevent progression to deep hemangioma. Pediatr Dermatol. 1993;10(1):77-80. doi:10.1111/j.1525-1470.1993.tb00021.x

11. Poetke M, Philipp C, Berlien HP. Flashlamp-pumped pulsed dye laser for hemangiomas in infancy: treatment of superficial vs mixed hemangiomas. Arch Dermatol. 2000;136(5):628-632. doi:10.1001/ archderm.136.5.628

12. Hartmann F, Lockmann A, Grönemeyer LL, et al. Nd:YAG and pulsed dye laser therapy in infantile haemangiomas: a retrospective analysis of 271 treated haemangiomas in 149 children. J Eur Acad Dermatol Venereol. 2017;31(8):1372-1379. doi:10.1111/jdv.14074

13. Alcántara-González J, Boixeda P, Truchuelo-Diez MT, et al. Infantile hemangiomas treated by sequential application of pulsed dye laser and Nd: YAG laser radiation: a retrospective study. Actas Dermosifiliogr. 2013;104(6):504-511.

14. Bastos JT, Balassiano LK, Mariano da Rocha CR, et al. Treatment of vascular lesions located in the lip and in the oral cavity with $\mathrm{Nd}$ : YAG laser. $J$ Cosmet Laser Ther. 2017;19(5):256-258. doi:10.1080/ 14764172.2017.1314503

15. Léauté-Labrèze C, Hoeger $P$, Mazereeuw-Hautier $J$, et al. A randomized, controlled trial of oral propranolol in infantile hemangioma. N Engl J Med. 2015;372(8):735-746. doi:10.1056/ NEJMoa1404710 
16. Baselga E, Dembowska-Baginska B, Przewratil P, et al. Efficacy of propranolol between 6 and 12 months of age in high-risk infantile hemangioma. Pediatrics. 2018;142(3):e20173866.

17. Kim KH, Choi TH, Choi Y, et al. Comparison of efficacy and safety between propranolol and steroid for infantile hemangioma: a randomized clinical trial. JAMA Dermatol. 2017;153(6):529-536. doi:10.1001/jamadermatol.2017.0250

18. Wu HW, Wang X, Zhang L, et al. Topical timolol vs. oral propranolol for the treatment of superficial infantile hemangiomas. Front Oncol. 2018;8:605. doi:10.3389/fonc.2018.00605

19. Izikson L, Anderson RR. Treatment endpoints for resistant port wine stains with a 755nm laser. J Cosmet Laser Ther. 2009;11(1):52-55. doi:10.1080/14764170802524452

20. Jin -W-W, Tong Y, Wu J-M, Quan -H-H, Gao Y. Observation on the effects of 595- nm pulsed dye laser and 755- nm long-pulsed alexandrite laser on sequential therapy of infantile hemangioma. J Cosmet Laser Ther. 2020;22(3):1-6.

21. Su W, Ke Y, Xue J. Beneficial effects of early treatment of infantile hemangiomas with a long-pulse Alexandrite laser. Lasers Surg Med. 2014;46(3):173-179. doi:10.1002/1sm.22221

22. Hemangioma and Vascular Malformation Group. Guidelines for the diagnosis and treatment of hemangioma and vascular malformations (2019 edition). J Tissue Eng Reconstr Surg. 2019;15(5):277-317.

23. McCormack HM, de L. Horne DJ, Sheather S. Clinical applications of visual analogue scales: a critical review. Psychol Med. 1988;18 (4):1007-1019. doi:10.1017/S0033291700009934

24. Anderson RR, Parrish JA. Selective photothermolysis: precise microsurgery by selective absorption of pulsed radiation. Science. 1983;220(4596):524-527. doi:10.1126/science.6836297

25. Wang F, Xu R, Xu Q, et al. Effect of laser therapy on plasma expression of VEGF and bFGF in infants with cutaneous hemangioma. Oncol Lett. 2017;13(3):1861-1865. doi:10.3892/ ol.2017.5640

26. Chang J, Most D, Bresnick S, et al. Proliferative hemangiomas: analysis of cytokine gene expression and angiogenesis. Plast Reconstr Surg. 1999;103(1):1-9; discussion 10. doi:10.1097/ 00006534-199901000-00001
27. Bruscino N, Bonan P, Cannarozzo G, et al. Laser use in infantile hemangiomas, when and how. Dermatol Ther. 2012;25(4):314-321. doi:10.1111/j.1529-8019.2012.01466.x

28. Goh CL. Flashlamp-pumped pulsed dye laser $(585 \mathrm{~nm})$ for the treatment of portwine stains-a study of treatment outcome in 94 Asian patients in Singapore. Singapore Med J. 2000;41(1):24-28.

29. Ying H, Zou Y, Yu W, et al. Prospective, open-label, rater-blinded and self-controlled pilot study of the treatment of proliferating superficial infantile hemangiomas with $0.5 \%$ topical timolol cream versus 595-nm pulsed dye laser. $J$ Dermatol. 2017;44(6):660-665. doi:10.1111/1346-8138.13747

30. Zeng M, Shen S, Chen W, Yang C, Liu S. Superficial hemangioma is better treated by topical 5-aminolevulinic followed by 595-nm pulsed dye laser therapy rather than 595-nm laser therapy alone. Lasers Med Sci. 2017;32(8):1889-1893. doi:10.1007/s10103-017-2304-9

31. Lin MY, Lin CS, Hu S, et al. The application of 595-nm pulsed dye laser for vascular anomalies in a Chinese population: a 10-year experience. J Cosmet Laser Ther. 2019;21(3):171-178. doi:10.1080/ 14764172.2018.1502450

32. Yang MU, Yaroslavsky AN, Farinelli WA, et al. Long-pulsed neodymium: yttrium-aluminum-garnet laser treatment for port-wine stains. J Am Acad Dermatol. 2005;52(3 Pt 1):480-490. doi:10.1016/j. jaad.2004.10.876

33. Ross EV, Meehan KJ, Gilbert S, Domankevitz Y. Optimal pulse durations for the treatment of leg telangiectasias with an alexandrite laser. Lasers Surg Med. 2009;41(2):104-109. doi:10.1002/1sm.20737

34. Wu Q, Shi Q, Long J, et al. [Usage and efficacy of timolol maleate eye drops in treatment of superficial infantile hemangioma]. Zhong Nan Da Xue Xue Bao Yi Xue Ban. 2017;42(6):657-661. Chinese.

\section{Publish your work in this journal}

Clinical, Cosmetic and Investigational Dermatology is an international, peer-reviewed, open access, online journal that focuses on the latest clinical and experimental research in all aspects of skin disease and cosmetic interventions. This journal is indexed on CAS.
The manuscript management system is completely online and includes a very quick and fair peer-review system, which is all easy to use. Visit http://www.dovepress.com/testimonials.php to read real quotes from published authors. 